\title{
Technological Entrepreneurship: A Multilevel Study
}

\author{
Héctor Montiel-Campos ${ }^{1 *}$, Yarissa Marcela Palma-Chorres ${ }^{2}$
}

\begin{abstract}
New technology-based firms play an important role in the business world, as they accelerate innovation processes and increase competitiveness. In the study of these businesses, it is necessary to involve variables of different levels of analysis. With the responses of 103 new technology-based firms, the relationship between variables at the individual, organizational, and contextual level was analyzed. The results show no clear and convincing relationship between entrepreneurial passion and creativity but there is between creativity and innovation. Also, the environmental dynamism showed no moderating influence on the passion-creative relationship but there was in the creativity-innovation relationship. The document presents a discussion of the main findings and conclusion of this work.
\end{abstract}

Keywords: new technology-based firms; entrepreneurial passion; creativity, innovation; environmental dynamism.

Submitted: May 25th 2016 / Approved: September 12th 2016

\section{Introduction}

In the study of technological entrepreneurship, the importance of the binomial individual-opportunity has been recognized as well as the impact it can have at an organizational level (Wright, Hmieleski, Siegel, \& Ensley, 2007). This is especially important in the field of startups, where the entrepreneur has strong influence on the organization's behavior, as it promotes a corporate culture and defines the direction of the firm (Montiel, Nuño, \& Solé, 2012).

New technology-based firms (NTBF) are special players in today's competitive environment, as they develop and offer products or services through the application of new technologies (Carayannopoulos, 2009). Because of the competitive nature of these firms, the entrepreneur must be more alert to changes and opportunities generated in the environment, which he should take and translate into better performance for the firm.

Despite the importance of the entrepreneur in the competitiveness of a NTBF, the question remains of how he influences the firm's performance. Therefore, the objective of this research is to explore the relationship between personal characteristics of the entrepreneur and the innovativeness of the firm. To address this approach, we used a model of multilevel research in the sense described by Hitt, Beamish, Jackson, and Mathieu (2007), which is increasingly recurrent in research on technological entrepreneurship (Baron \& Tang, 2011).

This research makes three important contributions. Based on existing theory (Cardon, Wincent, Singh, \& Drnovsek, 2009; Cardon, Foo, Shepherd, \& Wiklund, 2012), this work places entrepreneurial passion as a variable that influences the creativity of the entrepreneur. Also, in the study of innovation, the importance of creativity as a key ingredient stands out; however, it is necessary to study this relationship directly (Sarooghi, Libaers, \& Burkemper, 2015). Therefore, this study examines the relationship between creativity of the entrepreneur and the innovativeness of the firm. Finally, the environmental dynamism is included as a variable that moderates previously raised relationships. The environmental dynamism is important for the decision-making entrepreneur and influences the firm's innovativeness (Sarooghi et al., 2015).

The following section of this document shows the literature review and the establishment of the research hypothesis. Subsequently, the methodology is explained and the main results are shown. Finally, a discussion and the conclusion of this work are presented.

\section{Literature review and hypothesis}

\section{Entrepreneurial passion and creativity}

The literature review suggests that the affect plays an important role in the entrepreneurial process (Cardon, Gregoire, Stevens, \& Patel, 2013). In particular, a positive affect has been considered an element that triggers creative problem-solving (Baron \& Tang, 2011; Bledow, Rosing \& Frese, 2013). The conclusions in the work of Baas, De Dreu, and Nijstad (2008) suggest that positive affect increases creativity, but this is more likely when combined with high levels of activation. However, the results of George and Zhou (2002) are contradictory in this regard, so there remains insufficient evidence to generalize this relationship.

A line of research on the entrepreneurial passion has been recently added in the field of entrepreneurship, which is considered a positive affective state. The entrepreneurial passion is a positive and intense feeling that is accessible and is experienced by participating in business activities that are meaningful and important to the identity of the entrepreneur (Cardon et al., 2009).

In this perspective, passion allows the entrepreneur to creatively participate in the identification, invention, and exploration of new entre-

(1) School of Business and Economics, Universidad de las Américas Puebla, México

(2) Department of Assessment and Accreditation, Hosanna International University, Panamá

* Corresponding author: hector.montiel@udlap.mx 
preneurial opportunities. Previous work suggests that the passion of the entrepreneur, among other factors, significantly influences their behavior, particularly in generating entrepreneurial opportunities (Dalborg \& Wincent, 2015; Thorgren \& Wincent, 2015).

This argument leads us to consider that a strong emotional state, as is the passion, promotes the identification of new patterns, standards, or trends that indicate the possible existence of an entrepreneurial opportunity. In increasingly uncertain environments, where technology plays an important role, the entrepreneur is typically more creative when identifying and seizing an entrepreneurial opportunity. With this reasoning, the following hypothesis is proposed:

H1. The higher the passion of an entrepreneur NTBF, the higher will be your creativity to identify and exploit entrepreneurial opportunity.

\section{Creativity and innovation}

Creativity has been considered a precursor of innovation; and innovation generally leads to the successful implementation of a creative idea (Unsworth \& Luksyte, 2015). Creativity in the field of organizational theory is typically defined as "the generation or production of ideas that are both novel and useful" (George, 2007, p. 441). In this context, the reconfiguration of the resources of a business can be considered a creative act because such reconfiguration may lead to the exploitation of business opportunities and, consequently, innovation (Helfat \& Martin, 2015).

Entrepreneurs of NTBF significantly contribute to innovation, either through the decisions that guide the innovation process or by identifying new technologies that are of potential use in business, which can cause changes in the organizational structure (Helfat \& Eisenhardt, 2004). In addition, creativity is required not only to generate the initial idea for innovation but also for further development and adjustment thereof (Unsworth \& Luksyte, 2015).

The relationship between creativity and innovation has been approached for different reasons. First, the proposal to create and introduce new products and services in the market is a response to a problem that the entrepreneur has identified. In this process, creativity plays an important role in conceiving new ideas and offer solutions that can be implemented and is results-oriented; hence, Baer (2012) mentions that creativity is a necessary but insufficient condition for further innovation.

Second, a high interest in creativity by the entrepreneur of NTBF is essential to outline the business model, which will compete with the firm (Leibold, Voelpel, \& Tekie, 2004). Finally, Leiblein (2007) mentions that originality is important in the development of a new product, service, process, or business model. That is why organizations must be constantly changing or adapting their tactics and objectives. The approaches discussed above lead to the following hypothesis:

$\mathrm{H} 2$. The higher the creativity of the entrepreneur to identify and exploit entrepreneurial opportunities, the higher the number of innovations developed/adopted by a NTBF.

\section{Environmental dynamism}

The literature review shows that the environment has an influence on entrepreneurial actions, thereby demonstrating that the change in the environment leads to an increase in entrepreneurial activity (Edelman \& Yli-Renko, 2010). Changes in the environment (technological or regulation) create opportunities that can be identified by entrepreneurs. However, the speed with which changes occur is what characterizes a dynamic environment, which brings instability and high levels of uncertainty to the environment.

Environmental dynamism creates the possibility for entrepreneurs to make images of potential entrepreneurial opportunities, and these perceptions will help inspire creativity. Regarding the relationship between entrepreneurial passion and creativity, the work of Baas et al. (2008) indicates that the relationship "positive affect-creativity" is stronger when there are high levels of activation.

A dynamic environment can generate a high level of activation; therefore, an "entrepreneurial passion-creativity" relationship can be stronger. A dynamic environment, unlike a stable environment, involves greater risks, which brings more stress; this, in turn, causes high levels of activation (Stranks, 2005). For this reason, the "entrepreneurial passion-creativity" relationship is not isolated but occurs under the influence of a dynamic environment. Based on this reasoning, the following hypothesis is proposed.

H3. The environmental dynamism moderates the relationship between entrepreneurial passion and creativity of the entrepreneur; with that said, the relationship will be stronger in dynamic environments than in stable environments.

With regard to the relationship between creativity and innovation, so that ideas are materialized, it is necessary that the entrepreneur is motivated to consider these ideas and develop them until reaching innovation. Industries may experience a high dynamism due to changes in the technological capabilities of enterprises, the entry of new competitors, or by changes in customer preferences (Helfat \& Eisenhardt, 2004).

Highly dynamic conditions may limit the size advantage of large firms, which may represent opportunities for innovation for smaller firms. Smaller firms can be successful in a dynamic environment by developing newer technologies and using its flexibility to quickly introduce new products (Wiklund \& Shepherd, 2005). Usually, technological advances are rapidly disseminated in dynamic environments, which is why it is unlikely that a firm will survive without the constant development and updating of its product or service, no matter if it has to cannibalize its own products (Davila, Epstein, \& Shelton, 2006).

Moreover, Davila et al. (2006) mention that, in relatively stable environments, where competition depends more on efficiency and cost reduction, firms focus their efforts on incremental innovation processes. Hence, the dominant designs have more life in stable environments, which favors innovation opportunities revolve around the 
dominant design. That is why a creativity-innovation relationship in a dynamic environment should be stronger, as a result of the pressure to be generating ideas that help strengthen the competitive position of the firm through constant innovation. With this reasoning, the following hypothesis is proposed.

H4. The environmental dynamism moderates the relationship between entrepreneur creativity and innovation of NTBF, so that this relationship is stronger in dynamic environments than in stable environments.

\section{Methodology}

\section{Sample and procedure}

We used a database of firms that received support from business incubators in Mexico in order to identify those that would participate in the research. Also, firms that had previously participated in previous researches were identified.

To select the firms, two criteria were observed. First, the firm had to be technology-based, thus developing and providing products or services through the application of new technologies (Carayannopoulos, 2009). The second was that the firm should have started operations between two and five years prior to the implementation of the survey (Montiel et al., 2012). Thus, 173 firms were identified that met both criteria and whose operation centers were located in different states of Mexico.

The first contact with the firm was made by electronic means, specifically sending a letter to the contact person identified in the available information of the firm. The letter explained the project's nature and promised to share the results of work once the investigation was completed. Participants in this study were NTBF entrepreneurs.

The information was collected through the survey. Prior to the final application, a pilot test was conducted to incorporate feedback and corrections. The final survey was sent to the firms between April and November 2015: 105 of the initially identified 173 firms answered the survey. Two incomplete surveys were eliminated, so the final analysis was done with 103 surveys.

Entrepreneurs and their firms operated in a variety of industries, including agriculture, manufacturing, health, information technology, and design. Among the 103 entrepreneurs, 88\% were male, and the average age of the entire sample was 31.4 years. The average size of firms in terms of number of employees was 14.2

\section{Measurements}

To measure the entrepreneurial passion, this work used a subscale passion, developed by Cardon et al. (2013), for developing new organizations. This subscale is related to the growth and strengthening of the firm after it was founded (Cardon et al., 2009; 2013). Entrepreneurs who experience this kind of passion enjoy activities that are related to sales increase, new product development, the conquest of new markets, etc.
The passion for developing is measured through three items that assess the experience of intense positive feelings toward this activity and one item that evaluates the centrality of this activity for the self-identity of the individual. The four items were rated on a 5-point Likert scale. It is noteworthy that it cannot be combined the items of intense positive feelings with identity centrality, as they represent different aspects of passion (Cardon et al., 2013). The reliability analysis for the items that value the experience of positive feelings was 0.81

Creativity measuring was performed using the scale that has been used by Baron and Tang (2011). With this scale, entrepreneurs were asked to what extent its role and work as founder-manager of the firm is involved with these aspects: (1) promoting new ideas and approaches to solving customer problems; (2) generating new applications for existing technology; (3) taking risks; (4) generating radical ideas or proposals; and (5) developing innovative long-term applications. These items were rated on a 5-point Likert scale. Cronbach's alpha obtained in this scale was 0.75

Innovation was measured with items that represent the dimension of innovation in the concept of entrepreneurial orientation. From the entrepreneurial orientation, innovation is considered as the tendency of a firm to support new ideas and to foster creative processes in which to develop new products and services (Wiklund \& Shepherd, 2005). The scale consists of three items, which were evaluated in a 5-point semantic differential scale. Cronbach's alpha for this scale was 0.77

Environmental dynamism was measured with the 5-point semantic differential scale, as proposed by Miller and Friesen (1982), and consisted of three items. The alpha value was 0.78 . Finally, three control variables were used: age of the entrepreneur, gender $(0=$ female, $1=$ male $)$, and firm size (number of people directly employed by the firm).

\section{Analysis}

Once the information was collected through surveys, we created an analysis to test the validity of the scales. For this, the Cronbach's Alpha was calculated. All values were obtained above 0.70, which are considered acceptable (Hair, Black, Babin, \& Anderson, 2007). Although the passion for developing, creativity, innovation, and environmental dynamism are variables that conceptually can be distinguished from one another, a confirmatory factor analysis (CFA) was performed in order to empirically assess the discriminant validity.

For the CFA, two models were identified. The first one considered all the items on a single factor. This is a baseline model that estimates routinely, based on the idea that all variables can be captured in a single factor. The second model was obtained with four factors, ex-pecting that the four variables loaded in their respective factor.

Table 1 shows the threshold values for each of the test values $(\mathrm{Hu}$ \& Bentler, 1999) and the results for each model. The results indicate that the four-factor model is a better fit because all the items loaded signi-ficantly in their respective latent variables. This suggests satisfactory discriminant validity. 
Table 1. Overall fit indices for passion, creativity, innovation, and dynamism (threshold values in brackets)

\begin{tabular}{lccccc}
\hline Model & CFI $(>.90)$ & NFI $(>.90)$ & GFI $(>.90)$ & RMSEA $(<.05)$ & $\mathrm{c}^{2} / \mathrm{df}(<3.0)$ \\
\hline One factor & .68 & .86 & .70 & .101 & 4.22 \\
Four factors & .91 & .92 & .90 & .047 & 2.88 \\
\hline
\end{tabular}

To test the hypothesis correlation analysis, we determined the degree of relationship between variables. We further determined the degree of association between the study variables with hierarchical regression analysis and, thus, the test hypotheses. Thus, we identified 10 models in which independent variables were added, along with the multiplicative effect between them. Finally, the possibility of multicollinearity in the regression analysis was considered. To do this, tolerance was calculated and the variance inflation factor (VIF-test) was done. A lower than 0.20 tolerance value and/or VIF value greater than 5 indicated a multicollinearity problem (O'Brien, 2007). The results of these tests indicated that the regression analysis showed no multicollinearity.

\section{Results}

Table 2 shows the descriptive statistics and correlations between the variables involved in the study. An analysis of correlation coefficients shows a positive relationship between the two dimensions that make up the passion for developing, that is, between intense positive feelings and identity centrality $(r=0.23 ; p<0.05)$. Also, these two variables are positively related to creativity $(r=0.27, p<0.05$ and $r=$ $0.19, p<0.05$ respectively). Creativity, in turn, is positively related to innovation $(r=0.25, p<0.01)$.

Table 2. Descriptive statistics and correlations

\begin{tabular}{|c|c|c|c|c|c|c|c|c|c|c|}
\hline Variables & Average & S.D. & 1 & 2 & 3 & 4 & 5 & 6 & 7 & 8 \\
\hline 1. Age & 35.40 & 7.13 & 1.00 & & & & & & & \\
\hline 2. Gender & .87 & .20 & -.10 & 1.00 & & & & & & \\
\hline 3. Size & 9.11 & 2.65 & .05 & .00 & 1.00 & & & & & \\
\hline 4. Passion - IPF & 4.31 & .25 & .08 & .13 & .15 & 1.00 & & & & \\
\hline 5. Passion $-\mathrm{IC}^{\mathrm{b}}$ & 3.97 & .36 & .02 & .15 & .13 & $.23^{\star}$ & 1.00 & & & \\
\hline 6. Creativity & 4.05 & .41 & -.09 & .07 & .05 & $.27^{*}$ & $.19^{*}$ & 1.00 & & \\
\hline 7. Dynamism & 3.58 & .42 & .00 & .14 & .01 & -.08 & -.03 & $.09^{*}$ & 1.00 & \\
\hline 8. Innovation & 3.97 & .22 & .04 & .07 & $.08^{*}$ & .17 & 14 & $25^{* *}$ & 0.11 & 1.00 \\
\hline
\end{tabular}

${ }^{\mathrm{a}}$ Intense Positive Feelings; ${ }^{\mathrm{b}}$ Identity Centrality ${ }^{*} p<.05 ;{ }^{* *} p<0.01$

To test the hypothesis, hierarchical regression analysis was performed. Hypothesis 1 states that the entrepreneurial passion is positively related to the entrepreneur's creativity level. The results shown in Model 2 of Table 3 indicate that intense feelings are significantly related to the level of creativity $(B=0.19, p<0.01)$, but not the intense centrality ( $B=0.16$, not significant). When both dimensions are considered at the same time, its relationship to creativity is better. Model 3 shows that the combined effect of intense feelings and centrality has a better relationship with creativity $(B=0.23, p<0.01)$. These results lead us to partially accept Hypothesis 1 because the idea of centrality is not shown as significant.
With regard to Hypothesis 3, which referred to the moderator effect of the environmental dynamism in the passion-creative relationship, Model 5 of Table 3 shows that the dynamism does not have an influence on the relationship between intense positive feelings and creativity ( $B=0.20$, not significant) and the relationship between centrality and creativity, in which there is no significance $(B=0.13$, no significance). This result holds at the time we considered the combined effect of intense positive feelings, centrality, and environmental dynamism, which can be seen in Model 6, in which there is no significance (B $=0.22$, not significant). This result leads us to reject Hypothesis 3, considering that the dynamism of the environment does not have a moderating effect on the passion-creative relationship. 
Table 3. Relationship entrepreneurial passion-creativity and the moderating effect of environmental dynamism

\begin{tabular}{|c|c|c|c|c|c|c|}
\hline \multirow[t]{2}{*}{ Variables } & \multicolumn{6}{|l|}{ Creativity } \\
\hline & Model 1 & Model 2 & Model 3 & Model 4 & Model 5 & Model 6 \\
\hline Age & .17 & .11 & .08 & .01 & .01 & .02 \\
\hline Gender & .00 & .02 & .02 & .04 & .02 & .02 \\
\hline Size & .19 & .09 & .04 & .00 & .00 & .01 \\
\hline $\mathrm{IPF}^{\mathrm{a}}$ & & $.19^{* *}$ & $.17^{\star}$ & $.18^{\star}$ & $.21^{\star}$ & $.22^{*}$ \\
\hline $\mathrm{IC}^{\mathrm{b}}$ & & .16 & .22 & .19 & .22 & .17 \\
\hline $\mathrm{IPF}^{\mathrm{a} \star} \mathrm{IC}^{\mathrm{b}}$ & & & $.23^{*}$ & $.21^{*}$ & $.23^{*}$ & $.21^{*}$ \\
\hline Dynamism & & & & .22 & .14 & .16 \\
\hline $\mathrm{IPF}^{\mathrm{a} *}$ Dynamism & & & & & .20 & .20 \\
\hline $\mathrm{IC}^{\mathrm{b} \star}$ Dynamism & & & & & .13 & .10 \\
\hline $\mathrm{IPF}^{\mathrm{a}}{ }^{\mathrm{I}} \mathrm{C}^{\mathrm{b}}$ Dynamism & & & & & & .22 \\
\hline $\mathrm{R}^{2}$ & .03 & .11 & .16 & .17 & .19 & .21 \\
\hline Adjusted $\mathrm{R}^{2}$ & .02 & .09 & .15 & .15 & .18 & .19 \\
\hline
\end{tabular}

The results that analyze the creativity-innovation relationship and the moderating effect of environmental dynamism in this relationship can be seen in Table 4. Hypothesis 2 states that, while the greater the entrepreneur's creativity, the greater the number of innovations the firm developed or adopted. Model 2 of Table 3 shows a positive and significant relationship between creativity and innovation of the firm
$(\mathrm{B}=0.28, p<0.01)$. Thus Hypothesis 2 is accepted. In regards to the moderator effect of the environment dynamism in creativity-innovation relationship (Hypothesis 4), it is shown in Model 4 that the dynamism itself exerts a moderating effect on the relationship between creativity and innovation $(\mathrm{B}=0.30, p<0.01)$. Thus Hypothesis 4 is accepted.

Table 4. Relationship creativity-innovation and the moderating effect of environmental dynamism

\begin{tabular}{|c|c|c|c|c|}
\hline \multirow[t]{2}{*}{ Variables } & \multicolumn{4}{|l|}{ Innovation } \\
\hline & Model 1 & Model 2 & Model 3 & Model 4 \\
\hline Age & .16 & .13 & .14 & .15 \\
\hline Gender & .05 & .08 & .06 & .08 \\
\hline Size & .21 & .12 & .05 & .06 \\
\hline Creativity & & $.28^{* *}$ & $.23^{*}$ & $.21^{\times}$ \\
\hline Dynamism & & & $.29^{*}$ & $.27^{\times}$ \\
\hline Creativity ${ }^{*}$ Dynamism & & & & $.30^{x}$ \\
\hline $\mathrm{R}^{2}$ & .02 & .13 & .16 & .19 \\
\hline Adjusted $\mathrm{R}^{2}$ & .01 & .11 & .14 & .18 \\
\hline
\end{tabular}

\section{Discussion}

This paper provides empirical evidence of the relationship between variables that are at different levels of analysis: passion and creativity at the individual level, innovation at the organizational level, and environmental dynamism at the context level. The results indicate that the passion for developing, in one of its two dimensions (intense positive feelings), has a significant relationship with creativity. This was previously discussed in the literature (Baas et al., 2008). However, the second dimension, the passion for developing (identity centrality), did not show significance.
Strictly speaking, Cardon et al. (2013) noted that the two dimensions of passion should be equally important; however, in the results obtained here, only one dimension showed significance. In general, previous studies suggest that the affect brings benefits to the activities of the entrepreneur. However, some studies have already shown bucking this trend (Baron, Hmieleski, \& Henry, 2012), something that also can be discussed with the results obtained here. Moreover, the results confirm a significant relationship between creativity and innovation, as is indicated by previous works (Helfat \& Martin, 2015; Baer, 2012). 
In the scope of this work, it was considered that the relationship previously discussed was not isolated, but there was a moderating effect of the environment. This effect was presented in the relationship between creativity and innovation but not in the relationship between passion and creativity. In other words, the relationship between creativity and innovation is stronger in dynamic environments than it is in stable environments, which coincides with previous work (Wiklund \& Shepherd, 2005).

The four variables used in this research are complex; thus, for measurements, we used scales that have previously been used. The scale of the passion for developing is the most recent. Not enough jobs have tested this scale, however. Future work should consider this aspect to enhance the results.

The relationship that arises in this work is that the entrepreneurial passion influences innovation through creativity. However, it can be considered that other variables share the same role, so future work should consider the mediating effect on other variables in the entrepreneurial passion-innovation relationship. Finally, this work does not identify the mechanisms through which the environmental dynamism moderates the relationship between entrepreneurial passion and creativity and between creativity and innovation; thus, future work should be made in this matter.

\section{Conclusion}

This work adds to the recent initiative to study the effect of passion in the business process. That is why "passion" was studied as a predecessor variable of creativity. It also supported the proposal to study more openly the relationship between creativity and innovation in order to better understand the role of the entrepreneur in this process in NTBF. In addition, the effect of the context in these relationships is studied. This aspect becomes more important in the reality of a new firm, especially when competitiveness is based on technological development.

In short, the results of this work contribute to different lines of research, which have been exposed throughout this paper. The results also reinforce the need to carry out multilevel studies to consider different variables at different levels of analysis at the same time due to the nature of the business process. This becomes especially important in the field of NTBF, as it accelerates innovation processes and regenerates businesses. The study of technological entrepreneurship has a long way to go, and there is confidence to believe that this work has made a small contribution.

\section{References}

Baas, M., De Dreu, C.K.W., \& Nijstad, B.A. (2008). A meta-analysis of 25 years of mood-creativity Research: hedonic tone, activation, or regulatory focus? Psychological Bulletin, 134(6), 779-806. http://dx.doi. org/10.1037/a0012815
Baer, M. (2012). Putting creativity to work: The implementation of creative ideas in organizations. Academy of Management Journal, 55(5): 1102-1119. http://dx.doi.org/10.5465/amj.2009.0470

Baron, R.A., \& Tang, J. (2011). The role of entrepreneurs in firm-level innovation: joint effects of positive affect, creativity, and environmental dynamism. Journal of Business Venturing, 26(1), 49-60. http:// dx.doi.org/10.1016/j.jbusvent.2009.06.002

Baron, R.A., Hmieleski, K.M., \& Henry, R.A. (2012). Entrepreneur's dispositional positive affect: the potential benefits -and potential costs- of being "up". Journal of Business Venturing, 27(3), 310-324. http://dx.doi.org/10.1016/j.jbusvent.2011.04.002

Bledow, R., Rosing, K., \& Frese, M. (2013). A dynamic perspective on affect and creativity. Academy of Management Journal, 56(2), 432-450. http://dx.doi.org/10.5465/amj.2010.0894

Cardon, M.S., Wincent, J., Singh, J., \& Drnovsek, M. (2009). The nature and experience of entrepreneurial passion. Academy of Management Review, 34(3), 511-532. http://dx.doi.org/10.5465/ amr.2009.40633190

Cardon, M.S., Foo, M.D., Shepherd, D.A., \& Wiklund, J. (2012). Exploring the heart: Entrepreneurial emotion is a hot topic. Entrepreneurship Theory and Practice, 36(1), 1-10. http://dx.doi.org/10.1111/ j.1540-6520.2011.00501.x

Cardon, M.S., Gregoire, D.A., Stevens, C.E., \& Patel, P. (2013). Measuring entrepreneurial passion: Conceptual foundations and scale validation. Journal of Business Venturing, 28(3), 373-396. http://dx.doi. org/10.1016/j.jbusvent.2012.03.003

Carayannopoulos, S. (2009). How technology-based new firms leverage newness and smallness to commercialize disruptive technologies. Entrepreneurship Theory and Practice, 33(2), 419-438. http:// dx.doi.org/10.1111/j.1540-6520.2009.00297.x

Dalborg, C., \& Wincent, J. (2015). The idea is not enough: The role of self-efficacy in mediating the relationship between pull entrepreneurship and founder passion - a research note. International Small Business Journal, 33(8), 974-984. http://dx.doi. org/10.1177/0266242614543336

Davila, T., Epstein, J., \& Shelton, R. (2006). Making innovation work: how to manage it, measure it, and profit from it. Upper Saddle River: Wharton School Publishing.

Edelman, L., \& Yli-Renko, H. (2010). The impact of environment and entrepreneurial perceptions on venture-creation efforts: bridging the discovery and creation views of entrepreneurship. Entrepreneurship Theory and Practice, 34(5), 833-856. http://dx.doi. org/10.1111/j.1540-6520.2010.00395.x 
George, J.M., \& Zhou, J., 2002. Dual tuning in a supportive context: joint contributions of positive mood, negative mood, and supervisory behaviors to employee creativity. Academy of Management Journal, 50(3), 605-622. http://dx.doi.org/10.5465/ amj.2007.25525934

George, J.M. (2007). Creativity in organizations. Academy of Management Annals, 1(1), 439-477. http://dx.doi.org/10.1080/078559814

Hair, J.F., Black, W. C., Babin, B. J., \& Anderson, R. E. (2007). Multivariate data analysis. (7ed). Englewood Cliffs, New Jersey: Prentice Hall.

Helfat, C.E., \& Eisenhardt, K.M. (2004). Intertemporal economies of scope, organizational modularity, and the dynamics of diversification. Strategic Management Journal, 25(13), 1217-1232. http://dx.doi. org/10.1002/smj.427

Helfat, C.E., \& Martin, J.A. (2015). Dynamic managerial capabilities: A perspective on the relationship betweem managers, creativity, and innovation in organizations. In C.E. Shalley, M.A. Hitt, J. Zhou (Eds.), The Oxford handbook of creativity, innovation and entrepreneurship (pp. 421-429). New York: Oxford University Press.

Hitt, M.A., Beamish, P.W., Jackson, S.E., \& Mathieu, J.E. (2007). Building theoretical and empirical bridges across level: multilevel research in management. Academy of Management Journal, 50(6), 1385-1399. http://dx.doi.org/10.5465/amj.2007.28166219

Hu, L.T., \& Bentler, P.M. (1999). Cutoff criteria for fit indices in covariance structure analysis: conventional criteria vs new alternatives. Structural Equation Modeling: A Multidisciplinary Journal, 6(1), 1-55. http://dx.doi.org/10.1080/10705519909540118

Leiblein, M.J. (2007). Environment, organization, and innovation: how entrepreneurial decisions affect innovative success. Strategic Entrepreneurship Journal, 1(1-2), 141-144. http://dx.doi.org/10.1002/sej.9

Leibold, M., Voelpel, S.C., \& Tekie, E.B. (2004). Managerial levers in cultivating new mental space for business innovation. South African Journal of Business Management, 35(4): 61-71.
Miller, D., \& Friesen, P.H. (1982). Innovation in conservative and entrepreneurial firms: Two models of strategic momentum. Strategic Management Journal, 3(1), 1-25. http://dx.doi.org/10.1002/ smj.4250030102

Montiel, C.H., Nuño, P.J.P., \& Solé, P.F. (2012). The entrepreneurial orientation-dominant logic-performance relationship in new ventures: An exploratory quantitative study. Brazilian Administration Review, 9(2), 60-77.

O'Brien, R.M. (2007). A causation regarding rules of thumb for variance inflation factors. Quality and Quantity, 41(5), 673-690. http:// dx.doi.org/10.1007/s11135-006-9018-6

Sarooghi, H., Libaers, D., \& Burkemperm A. (2015). Examining the relationship between creativity and innovation: A meta-analysis of organizational, cultural, and environmental factors. Journal of Business Venturing, 30(5), 714-731. http://dx.doi.org/10.1016/j.jbusvent.2014.12.003

Stranks, J. (2005). Stress at work. Burlington, MA: Elsevier Butterworth-Heinemann.

Thorgren, S., \& Wincent, J. (2015). Passion and habitual entrepreneurship. International Small Business Journal, 33(2), 216-227. http:// dx.doi.org/10.1177/0266242613487085

Unsworth, K.L., \& Luksyte, A. (2015). Is all creativity created equal? Exploring differences in the creativity processes across the creativity types. In C.E. Shalley, M.A. Hitt, J. Zhou (Eds.), The Oxford handbook of creativity, innovation and entrepreneurship (pp. 279-297). New York: Oxford University Press.

Wiklund, J. \& Shepherd, D. (2005). Entrepreneurial orientation and small business performance: a configurational approach. Journal of Business Venturing, 20(1), 71-91. http://dx.doi.org/10.1016/j.jbusvent.2004.01.001

Wright, M., Hmieleski, K.M., Siegel, D.S., \& Ensley, M.D. (2007). The role of human capital in technological entrepreneurship. Entrepreneurship Theory and Practice, 31(6), 791-806. http://dx.doi. org/10.1111/j.1540-6520.2007.00202.x 